\title{
A Study to Assess Patient Safety Culture amongst a Category of Hospital Staff of a Teaching Hospital
}

\author{
MV Rao ${ }^{1}$, Dayakar Thota 2 , P Srinivas ${ }^{3}$ \\ ${ }^{1}$ (Department of Hospital Administration, Kamineni Institute of Medical Sciences, India)
}

\begin{abstract}
Patient Safety is an important aspect of health care and is an issue of high concern globally, since the magnitude of the harm done to patients by preventable errors is alarming. It is essential for every health care institution and hence instilling Patient safety culture amongst all staff involved in health care delivery is of vital importance. A survey tool called "Hospital Survey on Patient Safety Culture Questionnaire” was developed by a private research organization under contract with, and funded by the Agency for Healthcare Research and Quality. The questionnaire comprises of Question Items, and measures the aspects of Safety Culture at identified levels. The tool was modified, minimally, to suit the requirement of the setting. The responses were analyzed using "Data Entry and Analysis Tool" software from Agency for Healthcare Research and Quality. Analysis of the responses to the survey questionnaire showed that the average patient safety culture in the subject sample was $48 \%$ across all items of dimensions and levels of culture. The study, carried out in a section of hospital Staff, is an attempt to understand the subject and methods of assessing safety culture and helps in conducting a detailed study to cover all categories of the hospital staff. in order to assess overall safety culture in the organization towards Patient safety
\end{abstract}

Key words: Patient safety, Patient safety culture, Agency for Healthcare Research and Quality, Hospital Survey $n$ Patient Safety Culture Questionnaire.

\section{Introduction}

'First do no harm' is considered as a primary ethical principle of medical practice.

According to a report by the Institute Of Medicine, USA, the magnitude of the harm done by preventable errors is alarming. At least 44,000 people, and perhaps as many as 98,000 people, die in hospitals each year as a result of medical errors that could have been prevented, according to estimates from two major studies ${ }^{.}{ }^{(1)}$. The Fiftyfifth World Health Assembly passed a resolution "WHA55.18 "in May 2002, which called upon Member States to "pay the closest possible attention to the problem of patient safety and to establish and strengthen sciencebased systems necessary for improving patient safety and quality of care." ${ }^{2}$ Pressed with this consideration, in October 2004, WHO launched the World Alliance for Patient Safety. Since then, Patient safety has become an essential part of the Health care and issue of Concern worldwide and a lot of work has been done in many countries on issues relating to it.

\subsection{Definitions:}

Patient Safety $^{6}$ : Reduction of risk of unnecessary harm associated with health care to an acceptable minimum Safety Culture $^{7}$ : Safety culture of an organization is the product of individual and group values, attitudes, perceptions, competencies, and patterns of behavior that determine the commitment to, and the style and proficiency of an organization's health care and safety management.

\subsection{Causes Of Health Care Errors 8}

1.2.1 Human factors: Variations in healthcare providers' training and experience, fatigue, depression, and burnout; diverse patients, unfamiliar settings, and time pressures; failure to acknowledge the prevalence and seriousness of medical errors.

1.2.2 Poor communication: Miscommunication between units/health-care team/hospital facilities/community at clinical handovers ( as a study in Australia, 2007, found 15\% handovers resulting in adverse events), unclear lines of authority of physicians, nurses, and other care providers, similar names/ look alike / sound alike drugs., system inadequacies to share information about errors hampering analysis of contributory causes and improvement strategies.

1.3 Burden Of Unsafe Care 4 
1.3.1 Health Care Associated Infections (HCAI) 5 million HCAI estimated to occur in hospitals in Europe each year and 5-15\% of hospitalized patients acquiring HCAI - about $40 \%$ in ICUs. Of every 100 hospitalized patients at any given time, 7 in developed and 10 in developing countries will acquire at least one HCAI. Mortality from HCAI is estimated at $12 \%-80 \%$.

1.3.2 Medication errors:15 million were harmed and thousands killed due to medication errors in USA in 2006..In some countries, $70 \%$ of patients' medication histories contain errors.

1.3.3 Unsafe surgeries: While 234 million surgical procedures done worldwide per year, 7 million have complications, resulting in 1 million deaths.

1.3.4 Unsafe Injections: While, over 70\% of injections in primary health-care are said to be unnecessary, unsafe injections account for $33 \%$ of new HBV infections, $42 \%$ of $\mathrm{HCV}$ and $2 \%$ of all new HIV infections worldwide ${ }^{5}$

\subsection{Survey Tool On Patient Safety Culture 9}

As the need to measure the Safety Culture of a hospital was recognized, a measuring tool known as “ Hospital Survey On Patient Safety Culture (HSOPSC) Questionnaire" was developed by a private research organization under contract with , and funded by the Agency for Healthcare Research and Quality (AHRQ).

The questionnaire comprises of 44 Question Items, and measures the aspects of Safety Culture at three levels namely Unit-level Aspects (Dimensions-7, Items-24), Hospital-level aspects (Dimensions-3, Items-11) and Outcome variables (Dimensions-4, Items-9).

The survey tool was pilot tested and validated in hospitals across the United States.

Though the survey tool was developed to be general enough for use in most hospitals it can be modified/ customized by making minimal changes. As a caution, only those changes that are absolutely necessary may be made, to preserve reliability and overall validity of the survey, and to facilitate comparisons with other hospitals. Studies have been conducted using the HSOPSC questionnaire at Jimma University Specialized Hospital,

Southwest Ethiopia ${ }^{10}$, in some Lebanese hospitals ${ }^{11}$ and hospitals in Taiwan ${ }^{12}$, which demonstrate a positive relationship between organizational culture and safety outcomes for both patients and employees.

\subsection{Study design}

\section{Methods}

Cross sectional survey amongst select hospital staff in a 1060 bedded teaching hospital, to assess their awareness levels on Patient safety with an objective to measure the Safety Culture Dimensions. The scope of the survey was limited to one category of the hospital staff and not all. The study tool was "Hospital Survey On Patient Safety culture (HSOPSC) Questionnaire".

\subsection{Study participants}

Medical interns, rotating through all clinical departments and have worked in the concerned department for a minimum period of six months. They were working for more than 40 hours a week, and having direct interaction with patients.

\subsection{Sample size}

Though, according to ASHRQ guidelines for the Patient Safety Culture Survey, the ideal number of the samples required is 450 , since this being a pilot study; 90 subjects (20\%) were covered.

\subsection{Data Collection, Processing and Analysis}

The study participants were pre-informed about its aim and objectives and their consent was taken. The questionnaire was served by the surveyor and filled by the participant on the spot, so that any clarification required on any question item could be given while completing the questionnaire. Confidentiality was maintained. The Software used for analysis was Data entry and Analysis tool from AHRQ, which worked with Microsoft ${ }^{\circledR}$ Excel ${ }^{\circledR}$ and facilitated input of the individual-level data from the survey and automatically created tables and graphs to display survey results.

\section{Results And Discussion}

3.1While 90 survey questionnaires were distributed, 76 valid responses were received, giving a response rate of $84 \%$. Percentages of employee responses to specific survey items were grouped according to the safety culture dimensions. Analyses of the responses were represented in the Figs. 1 to 14 as per the dimensions of safety culture namely, Teamwork within units, Supervisor/Manager expectations \& actions promoting the patient safety, Organizational learning-continuous improvement, Management support for patient safety, Overall perceptions of patient safety, Feedback and communication about error, Communication openness, Frequency of events reported, Teamwork across units, Staffing, Handoffs \& Transitions and Nonpunitive response to error. 
Note:

(a) "R" = a negatively worded item

(b) Chart totals exclude missing \& may not sum to $100 \%$ due to rounding

(c) Missing respondents were $0 \%$

(d) Item data not displayed for fewer than 3 respondents

(e) Codes in Bracket of each item include the section/ number of the question in the Questionnaire. For example, A1 Indicates Section-A Question No.1
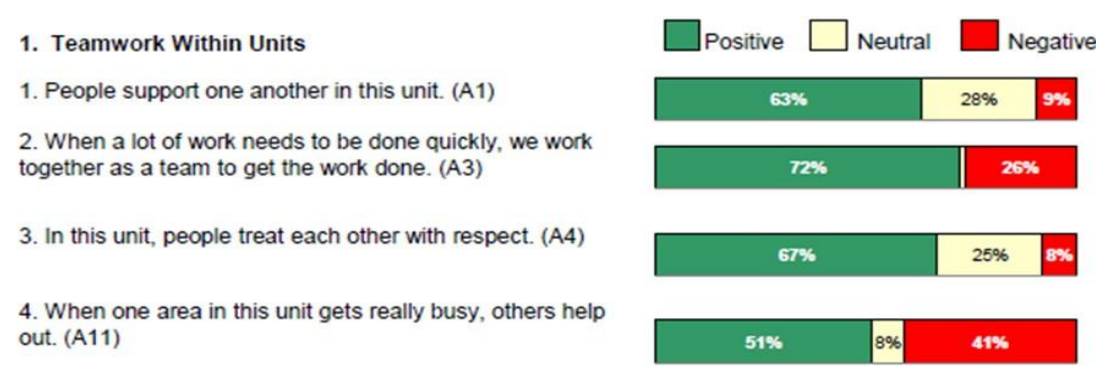

Figure 1: The dimension showed the teamwork within the units in terms of supporting, respecting each other was quite good
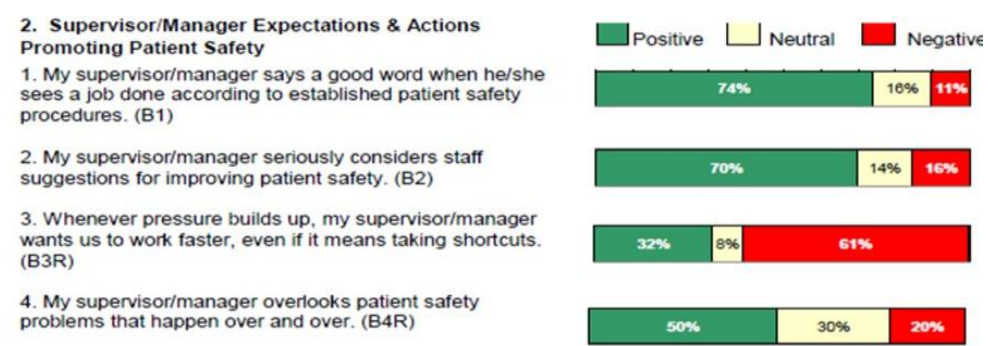

Figure 2: The dimension showed the Superior/Manager said a good word when the job was done according to established patient safety procedure but there was a tendency to take shortcuts and overlook patient safety

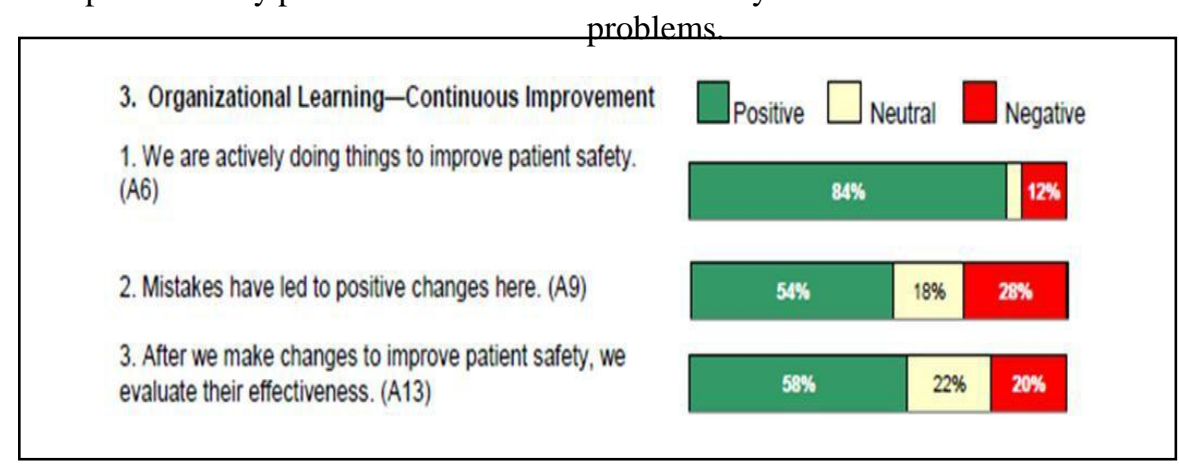

Figure 3

Figure 3: The dimension shows there was continuous improvement and learning regarding patient safety.

\begin{tabular}{|c|c|c|c|c|}
\hline $\begin{array}{l}\text { 1. Hospital management provides a work climate that } \\
\text { promotes patient safety. ( } F 1 \text { ) }\end{array}$ & $61 \%$ & & $30 \%$ & $9 \%$ \\
\hline $\begin{array}{l}\text { 2. The actions of hospital management show that patient } \\
\text { safety is a top priority. (F8) }\end{array}$ & $70 \%$ & & $13 \%$ & $17 \%$ \\
\hline $\begin{array}{l}\text { 3. Hospital management seems interested in patient safety } \\
\text { only after an adverse event happens. (F9R) }\end{array}$ & 36 & $32 \%$ & & \\
\hline
\end{tabular}

Figure 4

Figure 4: The dimension showed Management was supporting the patient safety and interested in it before any adverse event happens. 


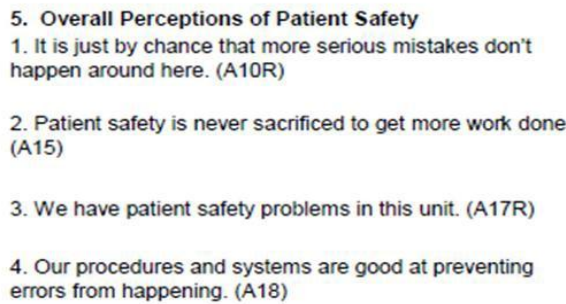

3. We have patient safety problems in this unit. (A17R)

4. Our procedures and systems are good at preventing errors from happening. (A18)

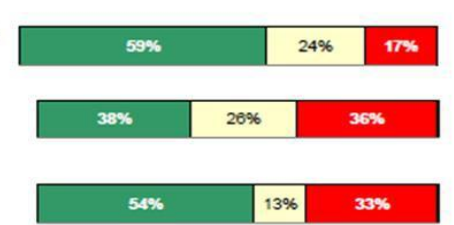

Figure 5: The dimension showed the patient safety procedures were good with scope of improvement and also patient safety was never compromised most of the times.

\begin{tabular}{l} 
6. Feedback and Communication About Error \\
1. We are given feedback about changes put into place \\
based on event reports. (C1) \\
\cline { 2 - 4 } Neutral
\end{tabular}

Figure 6

Figure 6: The dimension showed the feedback about changes put into place based on event reports was average and information and discussion on the errors happening was good.

\section{Communication Openness \\ 1. Staff will freely speak up if they see something that may negatively affect patient care. (C2) \\ 2. Staff feel free to question the decisions or actions of those with more authority. (C4) \\ 3. Staff are afraid to ask questions when something does not seem right. (C6R)}
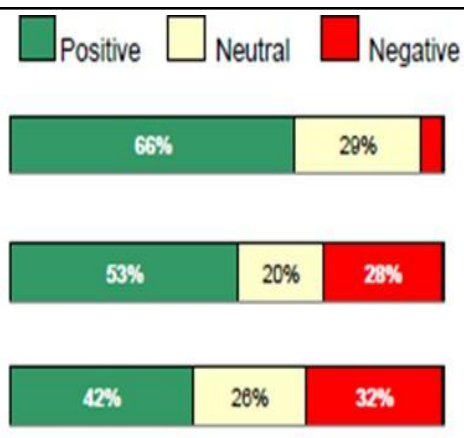

Figure 7

Figure 7: The dimension showed the communication openness of staff was good but sometimes were afraid to ask questions when something do not seem right.

\begin{tabular}{|c|c|c|c|}
\hline 8. Frequency of Events Reported & Positive & Neutral & Negative \\
\hline $\begin{array}{l}\text { 1. When a mistake is made, but is caught and corrected } \\
\text { before affecting the patient, how often is this reported? (D1) }\end{array}$ & $36 \%$ & $50 \%$ & $14 \%$ \\
\hline \multirow{2}{*}{$\begin{array}{l}\text { 2. When a mistake is made, but has no potential to harm } \\
\text { the patient, how often is this reported? (D2) }\end{array}$} & & & \\
\hline & $32 \%$ & $39 \%$ & $29 \%$ \\
\hline \multirow{2}{*}{$\begin{array}{l}\text { 3. When a mistake is made that could harm the patient, but } \\
\text { does not, how often is this reported? (D3) }\end{array}$} & & & \\
\hline & $28 \%$ & $54 \%$ & $18 \%$ \\
\hline
\end{tabular}

Figure 8: The dimension showed the reporting of the events when not causing harm was inadequate 
9. Teamwork Across Units

1. Hospital units do not coordinate well with each other. (F2R)

2. There is good cooperation among hospital units that need to work together. (F4)

3. It is often unpleasant to work with staff from other hospital units. (F6R)

4. Hospital units work well together to provide the best care for patients. (F10)
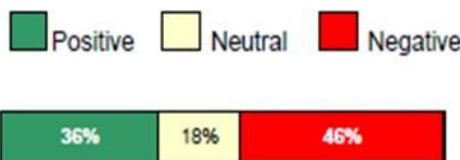

\begin{tabular}{|l|l|l|}
\hline $57 \%$ & $18 \%$ & $25 \%$ \\
\hline
\end{tabular}

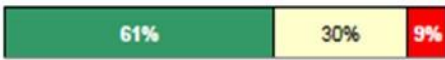

\begin{tabular}{|l|l|l|}
\hline $55 \%$ & $29 \%$ & $16 \%$ \\
\hline
\end{tabular}

Figure 9: The dimension showed the teamwork across the units was good.

\begin{tabular}{|c|c|c|c|c|}
\hline 10. Staffing & Positiv & & & $\mathrm{Neg}$ \\
\hline 1. We have enough staff to handle the workload. (A2) & 55 & & $20 \%$ & $25 \%$ \\
\hline $\begin{array}{l}\text { 2. Staff in this unit work longer hours than is best for patient } \\
\text { care. (A5R) }\end{array}$ & $21 \%$ & & $70 \%$ & \\
\hline $\begin{array}{l}\text { 3. We use more agency/temporary staff than is best for } \\
\text { patient care. (A7R) }\end{array}$ & $16 \%$ & $43 \%$ & & $41 \%$ \\
\hline $\begin{array}{l}\text { 4. We work in "crisis mode" trying to do too much, too } \\
\text { quickly. (A14R) }\end{array}$ & $24 \%$ & $28 \%$ & & $49 \%$ \\
\hline
\end{tabular}

Figure 10: The dimension showed there was enough staff to handle workload but in crisis mode there was tendency to do too much too quickly.

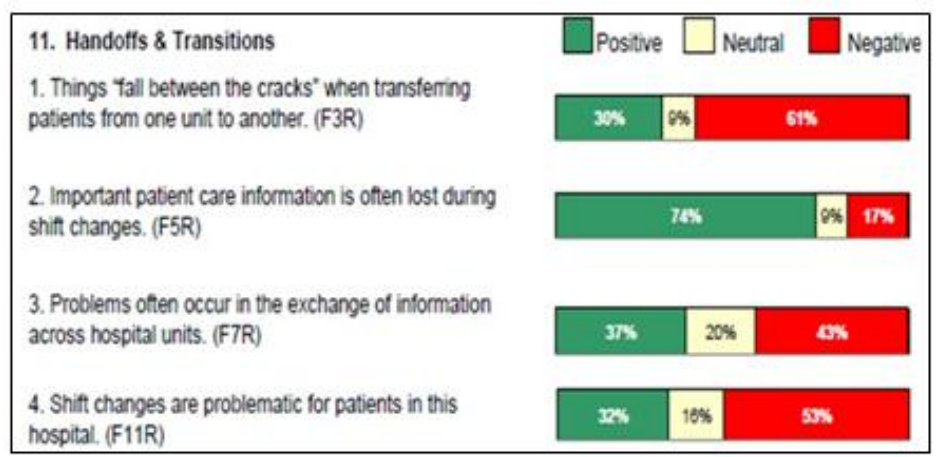

Figure 11: The dimension showed some of the patient information was lost during the handoff \& transitions but not much problematic.

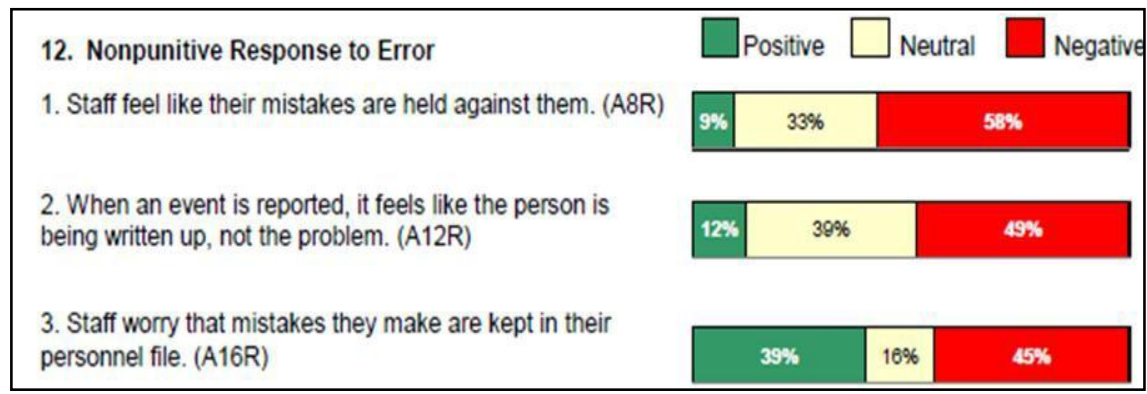

Figure 12: Survey of the dimension showed that mistakes were not held against the staff usually while some of the staff felt that the person was being written up and not the problem causing some worry. 


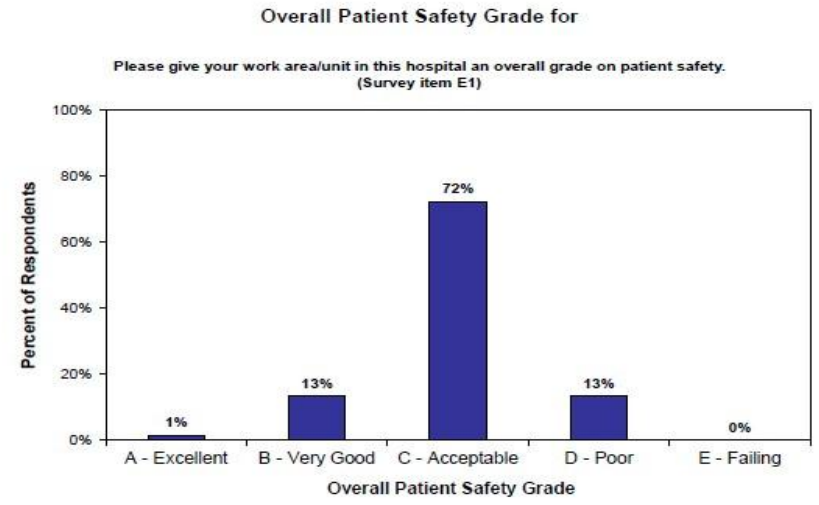

Figure-13: Regarding overall patient safety grade, maximum responses inferred acceptable level where as few of them responded as very good or poor.

Number of Events Reported for

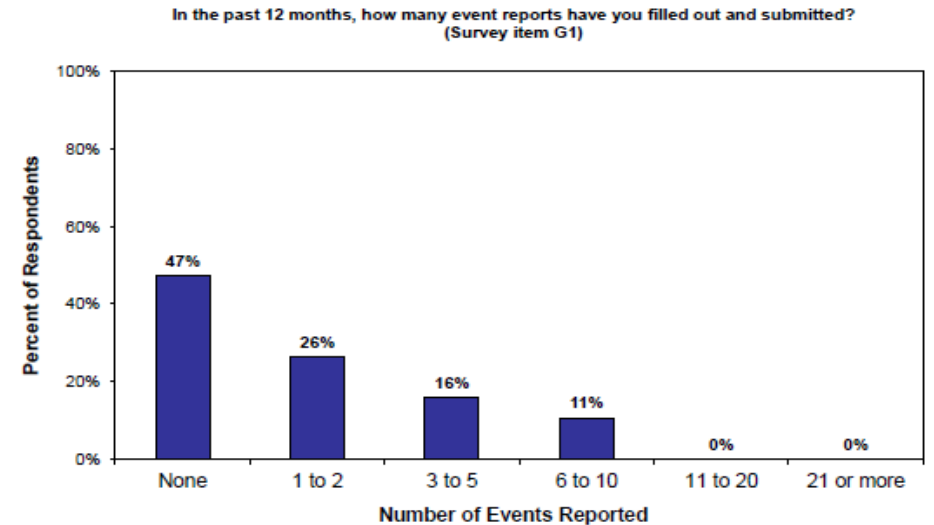

Figure-14: Responses to number of events reported showed very few reported events in past 12 months.

\subsection{Composite level Average percentage of Positive Responses, dimension wise:}

The composite average positive response to questions to each of the dimension, depicted in Table 1, showed that for dimensions like Team work within units, Organization learning and Feedback \& communication about error are more than $60 \%$. For dimensions like Overall perceptions of patient safety, Frequency of events reported, staffing, handoffs \& transitions, Non punitive response it was less than $50 \%$. The dimensions like Supervisor/Manager expectations \& actions promoting Patient safety, Management support for patient safety, Communication openness and Team work across units were averaged between 50-60\%.

The average Patient safety culture amongst the survey category of the hospital staff, across all items of dimensions and levels of culture, was measured to be $48 \%$.

The dimensions where the average was less than $50 \%$ need to be further improved upon in order to achieve a higher composite level average.

\begin{tabular}{|l|l|}
\hline Dimension & Positive response \\
\hline 1.Teamwork Within Units & $63 \%$ \\
\hline $\begin{array}{l}\text { Supervisor/Manager Expectations \& Actions Promoting } \\
\text { Patient Safety }\end{array}$ & $56 \%$ \\
\hline 3. Org Learning--Continuous Improvement & $65 \%$ \\
\hline 4. Management Support for Patient Safety & $55 \%$ \\
\hline 5. Overall Perceptions of Patient Safety & $41 \%$ \\
\hline 6. Feedback \& Communication About Error & $65 \%$ \\
\hline 7. Communication Openness & $54 \%$ \\
\hline
\end{tabular}




\begin{tabular}{|l|l|}
\hline 8. Frequency of Events Reported & $32 \%$ \\
\hline 9. Teamwork Across Units & $52 \%$ \\
\hline 10. Staffing & $26 \%$ \\
\hline 11. Handoffs \& Transitions & $43 \%$ \\
\hline 12. Non punitive Response to Error & $20 \%$ \\
\hline Average Across Composites & $48 \%$ \\
\hline
\end{tabular}

TABLE 1: Composite-Level Average with percentage of Positive Response, Dimension wise. Respondents: 76

\section{Conclusion}

Patient safety is a concern for every health care institution both ethically and legally and hence instilling Patient safety cultures amongst all staff involved in health care delivery is of vital importance. The tool, "Hospital Survey on Patient Safety Culture (HSOPSC) Questionnaire" helps in measuring this culture in a health care organization, to implement effective interventions towards achieving high level of patient safety. The study which has been carried out in a section of hospital staff, gives valuable insight into the subject to know the prevalent status of patient safety culture in them. Since it has been undertaken on a pilot basis, a detailed study covering all categories of the hospital staff who are involved in patient care in the different departments of the hospital, such as Medical, Nursing,

paramedical and administrative staff, would be necessary to understand the overall safety culture in the organization towards patient safety. Such surveys would help healthcare organizations to address the issues of patient safety, timely and effectively.

\section{Acknowledgements}

The authors express their sincere thanks to the Management and Administration of the Institution for according permission to conduct the study and help in making available their resources. Authors are grateful to the study participants for sparing their valuable time in responding to the questionnaire and providing inputs and also thanks many of the institutional staff for their support and coordination in making this study feasible.

\section{References}

[1] Kohn L T, Corrigan J M., Donaldson M S( Institute of Medicine). To err is human: Building a safer health system. Washington, DC: National Academy of press; 2000, 1

[2] World Health Organization. The Conceptual Framework for the International Classification for Patient Safety. Available at: http://www.who.int/patientsafety/taxonomy/icps_statement_of_purpose.pdf.

[3] Ranjan M., Nobhojit R, Sukhmeet P (2012) 'Patient Safety in India: Time to speed up our efforts to reduce avoidable harm', THE NATIONAL MEDICAL JOURNAL OF INDIA, VOL. 25 (NO. 3), 129-131.

[4] World Health Organization (2012). Fundamentals in Patient Safety, Available at: http://www.who.int/patientsafety/education/curriculum/course1_handout.pdf (Accessed: July, 2013).

[5] World Health Organization. The Conceptual Framework for the International Classification for Patient Safety. Available at: http://www.who.int/patientsafety/taxonomy/icps_statement_of_purpose.pdf, 106

[6] WHO-ICPS, 2009. In nutshell, Patient safety is "freedom from accidental injury due to medical care, or medical errors".

[7] World Health Organization. The Conceptual Framework for the International Classification for Patient Safety. Available at: http://www.who.int/patientsafety/taxonomy/icps_statement_of_purpose.pdf, 142

[8] Sharma G, Awasthi S, Dixit A, Sharma G. Patient safety risk assessment and risk management: A review on Indian hospitals. ChronYoung Sci 2011; 2:186-9115.

[9] Sorra JS, Nieva VF. Hospital Survey on Patient Safety Culture. (Prepared by Westat, under contract No. 290-96-0004). AHRQ Publication No. 04-0041. Rockville, MD: Agency for Healthcare Research and Quality. September 2004, 3

[10] Assefa,T., Woldie,M.,Ololo, S. and Woldemichael, K. (2012) Patient safety practices and medical errors: Perception of health care providers at Jimma University Specialized Hospital, Southwest Ethiopia. Open Journal of Preventive Medicine, 2, 162-170. [11] Fadi El-Jardali S, MahaJafar. The current state of patient safety culture in Lebanese hospitals: a study at baseline. International Journal for Quality in Health Care 2010; Volume 22, Number 5, 386-395S.

[12] Chen and Li. Measuring patient safety culture in Taiwan using the Hospital Survey on Patient Safety Culture (HSOPSC). BMC Health Services Research 2010; 10:152. 